\title{
Discrepancies in central review re-testing of patients with ER-positive and HER2-negative breast cancer in the OPTIMA prelim randomised clinical trial
}

\begin{abstract}
S E Pinder ${ }^{*}, 1$, A F Campbell ${ }^{2}$, J M S Bartlett ${ }^{3}$, A Marshall $^{2}$, D Allen ${ }^{4}$, M Falzon ${ }^{5}$, J A Dunn ${ }^{2}$, A Makris $^{6}$, $L_{\text {Hughes-Davies }}^{7}$ and R C Stein ${ }^{8}$ on behalf of OPTIMA Trial Management Group

${ }^{1}$ Division of Cancer Studies, King's College London, Guy's Hospital, Great Maze Pond, London SE1 9RT, UK; ${ }^{2}$ Warwick Clinical Trials Unit, University of Warwick, Gibbet Hill Campus, Coventry CV4 7AL, UK; ${ }^{3}$ Ontario Institute of Cancer Research, Toronto, Ontario M5G 0A3, Canada; ${ }^{4}$ UCL-Advanced Diagnostics, University College London, 21 University Street, London WC1E 6JJ, UK; ${ }^{5}$ Department of Pathology, University College London Hospitals, 235, Euston Road, London NW1 2BU, UK; ${ }^{6}$ Department of Clinical Oncology, Mount Vernon Cancer Centre, Mount Vernon Hospital, Northwood, HA6 2RN, UK; ${ }^{7}$ Oncology Centre, Addenbrooke's Hospital, Cambridge University Hospitals NHS Foundation Trust, Cambridge, UK and ${ }^{8}$ Department of Oncology, University College London Hospitals, London NW1 2PG, UK
\end{abstract}

Background: There is limited data on results of central re-testing of samples from patients with invasive breast cancer categorised in their local hospital laboratories as oestrogen receptor (ER) positive and human epidermal growth factor receptor homologue 2 (HER2) negative.

Methods: The Optimal Personalised Treatment of early breast cancer uslng Multiparameter Analysis preliminary study (OPTIMA prelim) was the feasibility phase of a randomised controlled trial to validate the use of multiparameter assay-directed chemotherapy decisions in the UK National Health Service (NHS). Eligibility criteria included ER positivity and HER2 negativity. Central re-testing of receptor status was mandatory.

Results: Of the 431 patients tested centrally, discrepant results between central and local laboratory results were identified in only 19 (4.4\%; 95\% confidence interval 2.5-6.3\%) patients (with 21 tumours). On central review, seven patients had cancers that were ER-negative (1.6\%) and 13 (3.0\%) patients with 15 tumours had HER2-positive disease, including one tumour discrepant for both biomarkers.

Conclusions: Central re-testing of receptor status of invasive breast cancers in the UK NHS setting shows a high level of reproducibility in categorising tumours as ER-positive and HER2-negative, and raises questions regarding the cost effectiveness and clinical value of central re-testing in this sub-group of breast cancers in this setting.

Oestrogen receptor (ER) and human epidermal growth factor receptor homologue 2 (HER2) are established biomarkers in invasive breast cancer and form the backbone of clinical decisionmaking related to targeted therapies in the adjuvant setting. Although data from external quality assurance schemes (such as
UK NEQAS ICC), successful participation in which is mandatory for UK laboratories, indicates excellent performance for testing these receptors in local laboratories nationally, there is relatively little published evidence comparing local results to central retesting of local ER and HER2 expression in large clinical trial data

*Correspondence: Professor SE Pinder; Sarah.pinder@kcl.ac.uk

Received 29 September 2016; revised 4 January 2017; accepted 16 January 2017; published online 21 February 2017

(C) 2017 Cancer Research UK. All rights reserved 0007-0920/17 
sets. In particular, information from central laboratory testing/ validation of series of invasive breast carcinomas that have been designated as ER-positive and HER2-negative is limited; reports have largely described data from central re-testing of breast cancers, which have been recorded as HER2-positive in local laboratories such as in the Breast Intergroup Trial N9831 (Roche et al, 2002; Perez et al, 2006). Some of these early publications have indicated alarming proportions of discrepancy in defining HER2 positivity. There are fewer publications comparing central repeat testing of hormone receptors from clinical trial samples but Viale et al (2007) examined 6291 of 8010 tumours from women in BIG1-98 and found that central review confirmed $97 \%$ of tumours were hormone receptor-positive (defined as ER and/or $\mathrm{PgR} \geqslant 10 \%)$. Using tissue microarrays of tumours in the Tamoxifen and Exemestane Adjuvant Multinational (TEAM) trial, of 4325 cases with sufficient material only 42 were ER-negative (0.99\%), of these 28 were $\mathrm{PgR}$ positive and only 14 ER-negative/PgR-negative tumours were identified (0.3\%; Bartlett et al, 2011b).

The accuracy of defining hormone receptor-positive and HER2negative invasive breast cancer in local centres is clearly vital for patient management outside of the clinical trial setting, but also has significant resource and cost implications within randomised trials where ER and/or HER2 are critical components of eligibility. The question remains whether local biomarker results are sufficiently robust to allow trialists to avoid the costly re-analysis of biomarkers in central laboratories to confirm patient eligibility. To address this question we have examined data in the UK setting within OPTIMA prelim.

\section{MATERIALS AND METHODS}

The Optimal Personalised Treatment of early breast cancer usIng Multiparameter Analysis preliminary study (OPTIMA prelim) (ISRCTN42400492) was the feasibility phase of a randomised controlled trial designed to validate the use of multiparameter assay-directed chemotherapy decisions in the UK National Health Service (Bartlett et al, 2013, 2016; Stein et al, 2016). Patients were aged $\geqslant 40$ years at entry with surgically treated ER-positive, HER2negative primary invasive breast cancer, with 1-9 involved axillary nodes or, if node negative, a tumour of at least $30 \mathrm{~mm}$ in maximum dimension. Patients were randomised to standard care (chemotherapy followed by endocrine therapy) or an Oncotype DX test (Genomic Health Inc., Redwood City, CA, USA) was performed on the surgically resected tumour to assign patients either to standard care (if 'Recurrence Score' (RS) was $>25$ ), or to endocrine therapy alone (if RS was $\leqslant 25$ ). In this feasibility study, ER and HER2 were both re-assessed by a central laboratory (UCL Advanced
Diagnostics) after registration into the trial to confirm eligibility prior to randomisation.

Oestrogen receptor was assessed centrally on whole tissue sections by immunohistochemistry (6F11; Leica Biosystems, Wetzlar, Germany) and an Allred score of 3 or more was regarded as positive, as per national guidance at that time (Harvey et al, 1999). If central ER results were discordant with the local report, and there was any doubt, the assay was repeated with a second antibody (EP1, Dako, Santa Clara, CA, USA). Human epidermal growth factor receptor homologue 2 was re-assessed centrally with dual-colour dual-hapten brightfield in situ hybridisation (DDISH) (Ventana Medical Systems, Tucson, AZ, USA) and, as per UK National Guidelines, a ratio of Her2 to chromosome 17 centromeric probe (CEP17) of 2.00-2.20 was considered to represent borderline/positive gene amplification, while a ratio of Her 2: CEP17 of $>2.20$ was regarded as Her2 gene amplification (Bartlett et al, 2011a). If DDISH proved unsuccessful, fluorescence in situ hybridization (FISH) was attempted using the HER2 PathVysion probe (HER2 PathVysion; Abbott Molecular, Des Plaines, IL, USA). Human epidermal growth factor receptor homologue 2 immunohistochemistry (4B5; Ventana Medical Systems) was applied in cases where no result was achievable by either HER2 ISH technique.

\section{RESULTS}

Between October 2012 and August 2014, 442 patients were registered into OPTIMA prelim, but 11 patients were subsequently withdrawn prior to central testing. Thus a total of 431 patients, recruited from 35 sites, had their tumours tested centrally. Nineteen patients with 21 tumours showed discrepancies in receptor status between local and central laboratory results $(4.4 \%$; $95 \%$ confidence interval $2.5-6.3 \%)$. The remaining 412 patients (95.6\%) with concordant results went on to be randomised into OPTIMA prelim.

Seven tumours in seven patients (1.6\%) were found to be ERnegative on central re-testing (Table 1). Two of the seven were heterogeneous, with an uncommon admixture of ER-negative and ER-positive cells identified in the surgically excised tumour. Two appear to represent true errors in local laboratory tests; as local laboratory re-testing on the same sample found the tumours to indeed be ER-negative (personal communication). In one case, an interpretive difference remained between the local and central testing; the core and the excision specimen were both re-assessed locally as showing low-level ER expression (Allred score 3 in the core biopsy) by the local pathologist. Unfortunately, despite liaison with the laboratories it has not been possible to discover whether ER status has been re-assessed locally for other two discrepant tumours.

Table 1. Details of the seven patients (from 431 patients registered and tested centrally) with discrepant oestrogen receptor results

\begin{tabular}{|c|c|c|c|c|}
\hline Patient & \multicolumn{3}{|c|}{ Central ER results } & Comment \\
\hline A & Negative & 0 & 0 & $\begin{array}{c}\text { Two clonality distinct tumours - part positive and part negative for ER. } \\
\text { Original ER on core biopsy. }\end{array}$ \\
\hline B & Negative & 0 & 0 & $\begin{array}{l}\text { ER repeated in local laboratory on core biopsy using different antibody } \\
\text { clone and negative staining for ER confirmed. }\end{array}$ \\
\hline C & Negative & 0 & 0 & ER retested locally and confirmed to be negative. \\
\hline $\mathrm{E}$ & Negative & 0 & 0 & Heterogenous tumour, at least focally ER-negative. \\
\hline $\mathrm{F}$ & Negative & 0 & 0 & \\
\hline G & Negative & 0 & 0 & Three tumours: two eligible, one ineligible \\
\hline
\end{tabular}


In total 15 tumours in 13 patients (3.0\%) from the 431 patients tested centrally were discrepant for HER2 results (Table 2). One patient had one tumour that was centrally categorised as ERnegative and also showed Her2 amplification (ratio of Her 2: CEP17 = 3.59). Seven others also showed Her 2 amplification (ratio of Her2: CEP17 ranged from 2.39 to 3.92). An additional patient had one tumour that was Her2 amplified and one tumour that was borderline amplified (ratio of Her2: CEP17 $=2.78$ and 2.11, respectively). The remaining four patients had tumours showing borderline Her2 gene amplification (ratio between 2.00 and 2.20); including one patient with two tumours both showing borderline amplification. Only 3 of the 15 tumours demonstrated what some consider 'high-level' gene amplification (ratio >3.00) (Starczynski et al, 2012) and none what others have described as 'high-grade' amplification (ratio $\geqslant 4.00$; Seol et al, 2012).

It has not been possible to ascertain if there has been repeat HER2 testing (immunohistochemistry, or FISH or DDISH) on all of these 13 cases; for five women (with seven tumours) the local team have managed the patient as per the central, HER2-positive, results without apparent re-testing. In three further cases data have not been obtainable. In four cases local re-testing has been undertaken: in two cases (one by FISH, other method uncertain) the local laboratory results have remained HER2-negative (both tumours borderline amplified by Her2: CEP17 ratio centrally), that is, results remaining discrepant; one case was agreed to be HER2-positive by re-testing locally by FISH; the final case on local repeat testing had a Her 2: CEP17 ratio of $>2.00$ but the local pathologist maintained that the tumour should be regarded as HER2-negative because of low average Her2 copy number. One case was negative immunohistochemically but showed Her2 gene amplification (3.92).

\section{DISCUSSION}

Central re-testing of HER2-positive breast cancers has shown high levels of variability in some clinical trials; for example, HER2 positivity was only confirmed in $85.8 \%$ of 2535 patients in the North Central Cancer Treatment Group N9831 intergroup adjuvant trial (Perez et al, 2006). Some of these trials, however, pre-date stringent guidelines for HER2 assessment and reporting, and the reasons for discordance are often not clear. The value of central re-testing of breast cancers defined locally as HER2negative as an eligibility criterion for other, more recent, clinical trials has not been well studied. Outwith clinical trials generally lower degrees of discrepancy have been reported (Vani et al, 2008; Kaufman et al, 2014), for example, Kaufman et al (2014) identified that only $4 \%$ of 552 patients with metastatic HER2-negative carcinoma (defined locally) in a large observational cohort were HER2-positive on central re-testing. These data are essentially similar to the results in our UK clinical trial where 3.5\% of tumours defined locally as HER2-negative were HER2-positive on central re-analysis.

These data highlight that $\sim 3 \%$ of patients could be being excluded from HER2-directed therapies due to a potentially faulty local result in real-world testing in the United Kingdom. However, of note, we report here the proportion of cases that are discordant between local and central laboratory testing. Although for two cases, repeat re-testing of the same samples locally confirmed the tumour was ER-negative (rather than ERpositive as initially reported), for others it is only possible to record that the other results were 'discordant'. It is not per se the case that the central laboratory is correct and the local laboratory inaccurate, as both adhere to the same quality assurance and reporting guidelines.

Central repeat testing of hormone receptor status from clinical trial samples have reported similar, albeit slightly higher, levels of difference between local and central laboratories than we have found. Viale et al (2007) examined 6291 of 8010 tumours from women in BIG1-98 and found that central review confirmed $97 \%$ of tumours were hormone receptor-positive, although this incorporated both ER and progesterone receptor, and with different cut-offs than applied as routine in the United Kingdom (i.e., defined as $\mathrm{ER}$ and/or $\mathrm{PgR} \geqslant 10 \%$ ). Indeed, the authors note

Table 2. Details of the 15 discrepant tumours (13 patients) for HER2 status

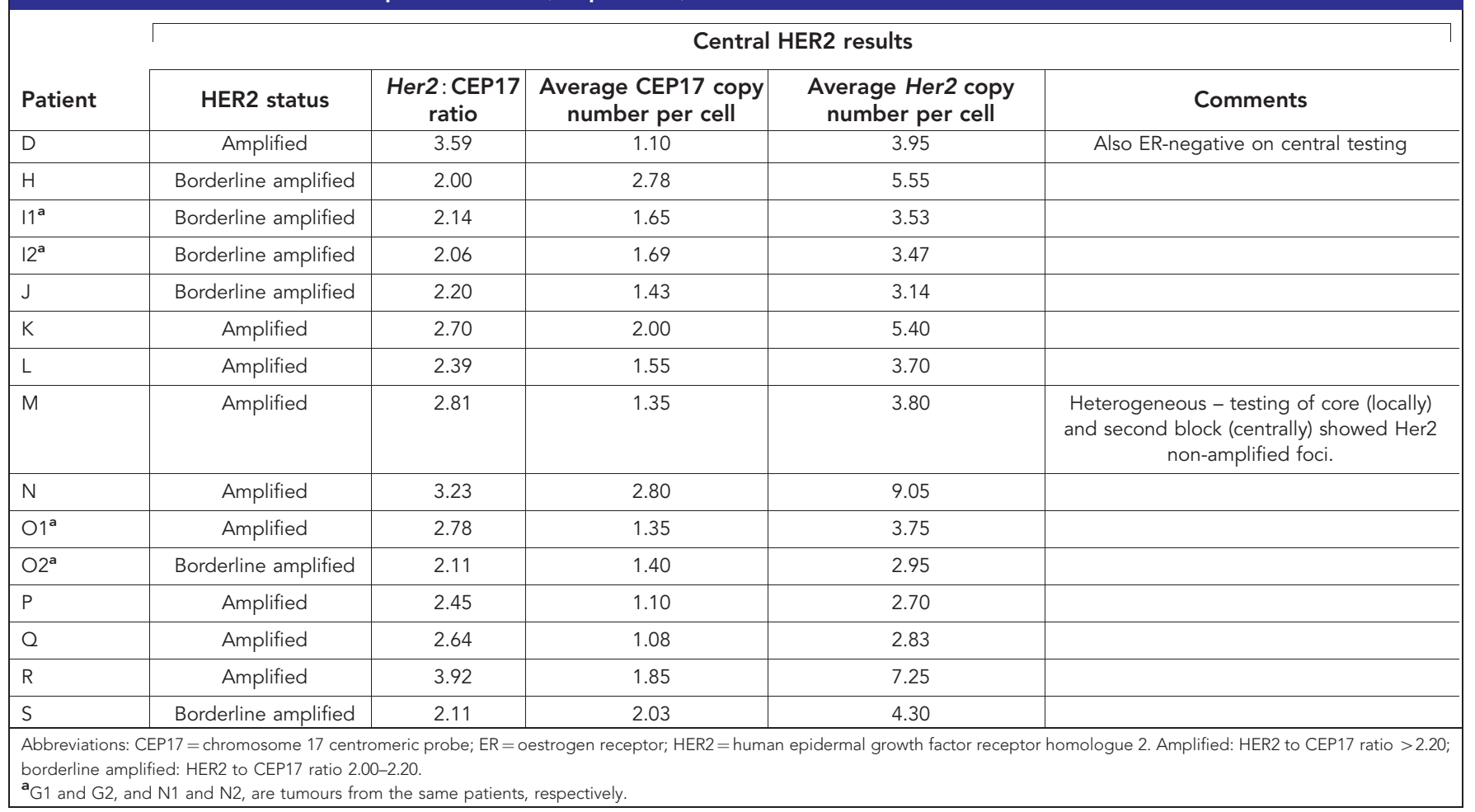


that, of 105 carcinomas that were reported locally as ER-negative, 73 had $>10 \%$, and 8 had $1-9 \%$ positive cells. This highlights the difficulty of non-standard definitions globally for hormone receptor positivity and the need for pathologists, as well as all other members of the multidisciplinary team, to be aware of study protocols and definitions.

Notwithstanding that these results compare favourably to the (albeit limited) published data, there are a number of possible explanations for discrepant results between local and central laboratories. Additional challenges include variation in methodology (e.g., immunohistochemistry vs FISH vs chromogenic in situ hybridisation (DDISH) for assessment of HER2 status), as well as differences in the antibody clones used, variation in the material assessed (cores vs surgical excision specimens) and pathologist interpretation. It is well recognised that variation between core biopsy specimens and surgical excision is uncommon $(<2 \%$ of cases showing heterogeneity; Arnedos et al, 2009; Lee et al, 2012), although this clearly does occur and may potentially explain variations in receptor status if different specimens are submitted for central testing than examined locally. Indeed, this variation appears to explain at least two of the seven cases with discrepant ER status in this study.

These potential discrepancies are all applicable even if the central review is undertaken in 'real time', that is, prior to patient randomisation, as in OPTIMA prelim. Nevertheless, particular care must be taken when analysing historical data on ER status, even in meta-analysis of clinical trials, or when comparing to present day results; data extracted from local reports may be based on entirely different methodologies; Collins et al (2008) examined (on TMA) 1851 cases where tissue and histology reports were available and highlighted that in $82 \%$ of the cases the original assays were biochemical. Even where immunohistochemistry was applied both locally and centrally as the technique of choice, agreement was only 92\% for ER status (310 of 336 specimens; Collins et al, 2008). Again, the $1.6 \%$ difference seen in OPTIMA prelim compares favourably.

Despite all the potential technical and interpretive differences in biomarker analysis, the results from OPTIMA prelim indicate good concordance between local laboratories and a central re-testing centre in the United Kingdom in classification of invasive breast cancers as ER-positive and HER2-negative. Such re-testing in large randomised clinical trials recruiting thousands of patients is very expensive and, in the setting of this group of patients (as opposed to HER2-positive disease, for example, where discrepancies may be higher), the value is questionable.

\section{ACKNOWLEDGEMENTS}

OPTIMA prelim (ISRCTN42400492) was funded by the National Institute for Health Research Health Technology Assessment Programme (project 10/34/01). RCS was supported by the National Institute for Health Research, University College London Hospitals Biomedical Research Centre.

\section{CONFLICT OF INTEREST}

The authors declare no conflict of interest.

\section{DISCLAIMER}

The views and opinions expressed therein are those of the authors and do not necessarily reflect those of the Health Technology Assessment Programme, NIHR, NHS or the Department of Health.

\section{REFERENCES}

Arnedos M, Nerurkar A, Osin P, A'Hern R, Smith IE, Dowsett M (2009) Discordance between core needle biopsy (CNB) and excisional biopsy (EB) for estrogen receptor (ER), progesterone receptor (PgR) and HER2 status in early breast cancer (EBC). Ann Oncol 20: 1948-1952.

Bartlett JM, Starczynski J, Atkey N, Kay E, O'Grady A, Gandy M, Ibrahim M, Jasani B, Ellis IO, Pinder SE, Walker RA (2011a) HER2 testing in the UK: recommendations for breast and gastric in-situ hybridisation methods. J Clin Pathol 64(8): 649-653.

Bartlett JM, Brookes CL, Robson T, van de Velde CJ, Billingham LJ, Campbell FM, Grant M, Hasenburg A, Hille ET, Kay C, Kieback DG, Putter H, Markopoulos C, Kranenbarg EM, Mallon EA, Dirix L, Seynaeve C, Rea D (2011b) Estrogen receptor and progesterone receptor as predictive biomarkers of response to endocrine therapy: a prospectively powered pathology study in the Tamoxifen and Exemestane Adjuvant Multinational trial. J Clin Oncol 29: 1531-1538.

Bartlett J, Canney P, Campbell A, Cameron D, Donovan J, Dunn J, Earl H, Francis A, Hall P, Harmer V, Higgins H, Hillier L, Hulme C, Hughes-Davies L, Makris A, Morgan A, Mccabe C, Pinder S, Poole C, Rea D, Stallard N, Stein R (2013) Selecting breast cancer patients for chemotherapy: the opening of the UK OPTIMA trial. Clin Oncol (R Coll Radiol) 25(2): 109-116.

Bartlett JM, Bayani J, Marshall A, Dunn JA, Campbell A, Cunningham C, Sobol MS, Hall PS, Poole CJ, Cameron DA, Earl HM, Rea DW, Macpherson IR, Canney P, Francis A, McCabe C, Pinder SE, Hughes-Davies L, Makris A, Stein RC, OPTIMA TMG (2016) Comparing breast cancer multiparameter tests in the OPTIMA Prelim Trial: no test is more equal than the others. J Natl Cancer Inst 108(9): pii: djw050.

Collins LC, Marotti JD, Baer HJ, Tamimi RM (2008) Comparison of estrogen receptor results from pathology reports with results from central laboratory testing. J Natl Cancer Inst 100(3): 218-221.

Harvey JM, Clark GM, Osborne CK, Allred DC (1999) Estrogen receptor status by immunohistochemistry is superior to the ligand-binding assay for predicting response to adjuvant endocrine therapy in breast cancer. $J$ Clin Oncol 17(5): 1474-1481.

Kaufman PA, Bloom KJ, Burris H, Gralow JR, Mayer M, Pegram M, Rugo HS, Swain SM, Yardley DA, Chau M, Lalla D, Yoo B, Brammer MG, Vogel CL (2014) Assessing the discordance rate between local and central HER2 testing in women with locally determined HER2 negative breast cancer. Cancer 120(17): 2657-2664.

Lee AH, Key HP, Bell JA, Hodi Z, Ellis IO (2012) Concordance of HER2 status assessed on needle core biopsy and surgical specimens of invasive carcinoma of the breast. Histopathology 60(6): 880-884.

Perez EA, Suman VJ, Davidson NE, Martino S, Kaufman PA, Lingle WL, Flynn PJ, Ingle JN, Visscher D, Jenkins RB (2006) HER2 testing by local, central, and reference laboratories in specimens from the North Central Cancer Treatment Group N9831 intergroup adjuvant trial. J Clin Oncol 24(19): 3032-3038.

Roche PC, Suman VJ, Jenkins RB, Davidson NE, Martino S, Kaufman PA, Addo FK, Murphy B, Ingle JN, Perez EA (2002) Concordance between local and central laboratory HER2 testing in the breast intergroup trial N9831. J Natl Cancer Inst 94(11): 855-857.

Seol H, Lee HJ, Choi Y, Lee HE, Kim YJ, Kim JH, Kang E, Kim SW, Park SY (2012) Intratumoral heterogeneity of HER2 gene amplification in breast cancer: its clinicopathological significance. Mod Pathol 25: 938-948.

Stein RC, Dunn JA, Bartlett JM, Campbell AF, Marshall A, Hall P, Rooshenas L, Morgan A, Poole C, Pinder SE, Cameron DA, Stallard N, Donovan JL, McCabe C, Hughes-Davies L, Makris A (2016) OPTIMA prelim: a randomised feasibility study of personalised care in the treatment of women with early breast cancer. Health Technol Assess 20(10): 1-202.

Starczynski J, Atkey N, Connelly Y, O'Grady T, Campbell FM, di Palma S, Wencyk P, Jasani B, Gandy M, Bartlett JM, UKNEQAS (2012) HER2 gene amplification in breast cancer: a rogues' gallery of challenging diagnostic cases: UKNEQAS interpretation guidelines and research recommendations. Am J Clin Pathol 137(4): 595-605.

Vani K, Sompuram SR, Fitzgibbons P, Bogen SA (2008) National HER2 proficiency test results using standardized quantitative controls: 
characterization of laboratory failures. Arch Pathol Lab Med 132(2): 211-216.

Viale G, Regan MM, Maiorano E, Mastropasqua MG, Dell'Orto P, Rasmussen BB, Raffoul J, Neven P, Orosz Z, Braye S, Ohlschlegel C, Thürlimann B, Gelber RD, Castiglione-Gertsch M, Price KN, Goldhirsch A, Gusterson BA, Coates AS (2007) Prognostic and predictive value of centrally reviewed expression of estrogen and progesterone receptors in a randomized trial comparing letrozole and tamoxifen adjuvant therapy for postmenopausal early breast cancer: BIG 1-98. J Clin Oncol 25(25): 3846-3852.
Walker RA, Bartlett JM, Dowsett M, Ellis IO, Hanby AM, Jasani B, Miller K, Pinder SE (2008) HER2 testing in the UK: further update to recommendations. J Clin Pathol 61(7): 818-824.

This work is published under the standard license to publish agreement. After 12 months the work will become freely available and the license terms will switch to a Creative Commons AttributionNonCommercial-Share Alike 4.0 Unported License. 